Андрей Олегович Рьбалов

\title{
ЭТЮД О ЗАЛОГЕ В РУССКОМ ПРАВЕ XV-XVII В.
}

Даже по сохранившимся документам можно судить, что залог был очень широко распространен на практике в рассматриваемый период. Однако до наших дней сохранилась лишь малая толика частноправовых актов той эпохи, ${ }^{1}$ и, возможно, ответов на некоторые вопросы мы не получим уже никогда. Тем не менее, история развития залога в русском праве была достаточно популярной темой в русской дореволюционной юридической литературе. После революции, однако, интерес к этой теме угас и в полной мере не возродился до сих пор. Между тем нельзя сказать, что тема может считаться исчерпанной. Скорее напротив, многие принципиальные вопросы остаются неразрешенными. В этом небольшом очерке сделана попытка обозреть основные проблемы, связанные с изучением залога в русском праве XV-XVII в.

Уже первые работы по истории залога в русском праве выявили две позиции, противостояние которых стало лейтмотивом последующих дискуссий. Так, Д.И. Мейер в своей известной работе 1855 г. пришел к выводу, что в старом русском праве залог не устанавливал право на чужую вещь, а означал переход права собственности от залогодателя к кредитору. ${ }^{2}$ В настоящее время эта точка зрения поддерживается, например, В.А. Беловым. ${ }^{3}$ Основывается такая позиция на двух столпах: во-первых, русское право того времени не знало залога недвижимости без передачи ее во владение залогодержателя, во-вторых, русское право тогда вообще не различало владение и право собственности. Эти утверждения, однако, вряд ли справедливы: случаи залога недвижимости без передачи владения встречаются довольно часто, а различие правового положения собственников (вотчичей, вотчинников) и лиц, обладавших земельными участками на иных основаниях (например, помещиков и на-

1 Акты служилых землевладельцев XV- начала XVII века. Т. 2. М.: Памятники исторической мысли, 1998. C. 4 .

2 Мейер Д.И. Древнее русское право залога // Мейер Д.И. Избранные произведения по гражданскому праву. М.: Центр ЮрИнфоР, 2003.

3 Белов В.А. «...Для дела правды и добра трудитесь до самой смерти вашей...» (Вступительная статья к книге: Мейер Д.И. Избранные произведения по гражданскому праву. М.: Центр ЮрИнфоР, 2003). С. 35 и след. 
нимателей) достаточно полно изучено; известны и примеры продажи залогодателем предмета залога, находящегося во владении залогодержателя.

Одновременно с Д.И. Мейером (в 1858 г.) другой авторитетнейший русский ученый - К.А. Неволин, - утверждал совсем иное. С точки зрения К.А. Неволина, залог по старому русскому праву мог приводить к переходу права собственности к залогодержателю в случае просрочки уплаты долга, иногда же несмотря на неуплату занятых денег в срок имущество оставалось собственностью закладчика, но заимодавец продолжал пользоваться заложенным имуществом. ${ }^{4}$

На то, что залог в русском праве, начиная, по крайней мере, с XVI в., в большинстве случаев представлял собой именно право на чужую вещь, не являясь продажей с условием о выкупе, писали практически все исследователи истории этого института: Л.А. Кассо, ${ }^{5}$ В. Удинцев, ${ }^{6}$ А.С. Звоницкий, ${ }^{7}$ М.Ф. Владимирский-Буданов. ${ }^{8}$ Например, А.С. Звоницкий категорически утверждал, что «в русском залоге абстрактное право собственности никогда не передавалось до срока залогодержателю, а передача владения, вследствие позднего возникновения этой формы, застала уже более или менее развитое правосознание, не смешивавшее ее с отчуждением; поэтому досрочное владение и пользование залогодержателя всегда носило производный, условный характер». ${ }^{9}$ C середины XVI в. права на землю подлежали внесению в вотчинные книги Поместного приказа, и в случае с залогом право собственности залогодержателя на заложенные имения могло регистрироваться лишь по просроченным закладным, но никак не с момента установления залога. При этом значение записи было настолько велико, что ст. 34 гл. 17 Соборного Уложения постановляла, что в случае, если недвижимость продана двум лицам, и одному она передана во владение, а за другим записана в книгах Поместного приказа, то собственником признавался указанный в книгах.

На практике, как отмечал еще К.А. Неволин, встречались практически все мыслимые формы залога. Очень популярным инструментом в русском праве XV-XVII в. был антихрез. Хотя само это название и не использовалось, суть отношений вполне описывается классическим определением: Si antichresis facta sit (fundi aut aedium)... in usuras fructus percipiat aut locando aut ipse percipiendo habitandoque. (D. 20.1.11.1). - В случае залога земли или дома по антихрезу,

\footnotetext{
4 Неволин К.А. История российских гражданских законов. Ч. З. М.: Статут, 2006. С. 143.

5 Кассо Л.А. Понятие о залоге в современном праве. М.: Статут, 1999. С. 199 и след.

6 Удинцев В.А. История займа. киев: Типография И.И. Чоколова, 1908.

7 Звоницкий А.С. О залоге по русскому праву. Издание книжного магазина Н.Я. Оглобина. киев, 1912.

8 Владимирский-Буданов М.Ф. Обзор истории русского права. М.: Издательский дом «Территория будущего», 2005.

9 Звоницкий А.С. О залоге по русскому праву. Издание книжного магазина Н.Я. Оглобина. киев, 1912. С. 170.
} 
кредитор вместо процентов собирает плоды либо путем сдачи в аренду, либо путем непосредственного сбора плодов, или проживая в доме.

В римском праве, как известно, антихрез получил распространение ближе к византийской эпохе, что связывается с наступлением экономического упадка и недостатком наличных денег, из-за чего должники были вынуждены отдавать землю во владение и в пользование кредитору с тем, что плоды поступали в покрытие процентов. ${ }^{10}$ По сходным причинам антихрез получил широкое распространение и в России, ${ }^{11}$ где не было серебряных рудников, и сырьем для чеканки монеты было серебро, поступавшее в результате международной торговли. На протяжении столетий в России общепринятой ставкой процентов за пользование заемными средствами (т.н. рост) было $20 \% .^{12}$ Понятно, что такой размер процентов лишь усугублял положение.

Поэтому антихрез представлял собой вполне приемлемый выход из трудного положения, поскольку платой за пользование капиталом выступало пользование заложенным имуществом, и размер этой платы регулировался размером этого последнего. Надо отметить, что антихрез не использовался в России для обхода запрета на взимание процентов (установленного ст. 255 Соборного Уложения 1649 г.) - судя по сохранившимся документам, этот запрет остался просто незамеченным, и необходимости обхода закона не было. Более того, после принятия Уложения сфера применения антихреза даже сократилась, уступив место платежу роста.

В некоторых случаях пользование кредитором заложенным имуществом покрывало лишь часть стоимости займа, а другую часть должник должен был вносить деньгами. Например, в одной из закладных 1523 г. указывается на то, что заемщику передается 300 рублей. В обеспечение он передает в залог свое недвижимое имущество. кредитор получает право пользоваться этой недвижимостью, что покрывает проценты с части долга в 200 рублей. Проценты со 100 рублей должник платит деньгами. ${ }^{13}$

Иногда недвижимость могла передаваться в пользование «за рост» только с момента просрочки возврата долга - см., например, закладную кабалу 1570 г. $^{14}$ Права кредитора пользоваться заложенным имуществом могли ограничиваться лишь определенным видом использования. Например, закладная

\footnotetext{
10 Римское частное право: Учебник. Под ред. И.Б. Новицкого и И.С. Петерского. М.: Юристъ, 1997. С. 344.

11 Неволин К.А. История российских гражданских законов. Ч. З. М.: Статут, 2006.

12 См., в частности: Рассказова Н.Ю. Ростовщические проценты // Основные проблемы частного права: Сборник статей к юбилею А.Л. Маковского. М.: Статут, 2010. С. 225.

13 Акты русского государства 1505-1526 гг. М.: Наука, 1975. С. 221.

14 Акты служилых землевладельцев. Т. 1. С. 219.
} 
1462 г. предусматривает, что кредитор вправе косить сено в заложенной ему деревне. $^{15}$

В случае неуплаты долга вовремя заложенная на условиях антихреза вотчина чаще всего поступала в собственность залогодержателя - по терминологии тех лет, закладная кабала обращалась в купчую. Установление пользования заложенным имуществом «за рост» вкупе с условием о lex commissoria позволяло кредитору чувствовать себя достаточно комфортно. Впрочем, наравне с этим условием встречается и другое - должник оставался собственником, а кредитор продолжал пользоваться заложенным имуществом до тех пор, пока должник не уплатит долг. Например, в соответствии с условиями закладной 1602 г. кредитор получал право пахать заложенную землю и косить на ней сено; в случае просрочки такое положение дел сохранялось до возврата долга. ${ }^{16}$

Впрочем, если заложенное имущество передавалось в «полное» пользование, с практической точки зрения сохранение права собственности за должником мало отличалось от перехода права собственности к кредитору. Стоимость земли в аграрную эпоху определялась исключительно производимыми на ней продуктами; иными словами, земля имела в первую очередь потребительскую, а не меновую ценность. Поэтому интерес кредитора заключался прежде всего в том, чтобы получить возможность получения плодов недвижимой вещи, а не право собственности на нее. ${ }^{17}$

Тем не менее, эти два вида антихреза четко разграничивались на практике при помощи словесных формул, неизменных на протяжении столетий. Это разграничение хорошо заметно на примере одной из закладных, по которой кредитор в случае просрочки продолжал пользоваться заложенной недвижимостью в счет процентов, однако если ему понадобятся деньги, должник должен был выплатить сумму долга или перевести на кредитора право собственности на предмет залога. ${ }^{18}$

Заложенное имущество могло и не передаваться во владение кредитору. В закладных можно встретить прямые указания на то, что до срока возврата долга должник сохраняет владение заложенным имуществом. ${ }^{19}$ И.А. Базанов писал о том, что залог без передачи владения широко практиковался в Пскове

\footnotetext{
15 Акты социально-экономической истории Северо-Восточной Руси конца XIV - начала XVI в. T. 2. М.: Издательство Академии наук СССР, 1958. С. 361.

16 Акты служилых землевладельцев XV - начала XVII века. T. 4. М.: Древлехранилище, 2008. С. 185.

17 Hubner R. A History of Germanic Private Law. The Lawbook Exchange, Ltd. New Jersey. P. 377.

18 Архив гостей Панкратьевых XVII - начала XVIII в. Т. 2. М.; СПб: Альянс-Архео, 2007. С. 71.

19 См., например: Акты Соловецкого м-ря 1572-1584. С. 180; Акты Иверского Святоозерского м-ря (15821706). СПб, 1878. С. 27; Шумаков С.А. Обзор «Грамот коллегии экономии». Вып. 5: Материалы по Владимиру, Гороховцу, Мурому, Суздалю, Юрьеву-Польскому и Вологде / Составитель Л.И. Шохин. М.: Древлехранилище, 2002. С. 237.
} 
в XVII в. ${ }^{20}$ В.Ф. Владимирский-Буданов высказывает также предположение, что в тех закладных, в которых указывается, что кредитор получает право пахать за рост земли только в случае просрочки, имеется в виду, что до того времени вещь остается во владении и пользовании должника. Им же высказано предположение, что об ипотеке нужно говорить и тогда, когда закладная говорит об установлении «поруки» вещи - т.е. о поручительстве, в котором поручителем выступает вещь. ${ }^{21}$ к таким случаям нужно отнести и те довольно экзотические примеры, когда должник в счет процентов «брал на себя обязанность предоставить кредитору плоды заложенной вещи, которая оставалась во владении должника». ${ }^{22}$

Сферой применения залога были, разумеется, заемные операции. Еще ст. 30 Псковской Судной грамоты устанавливала правило: займы больше рубля без залога не давать. Были выработаны достаточно строгие требования к форме договоров займа. Они должны были составляться исключительно в письменной форме - в форме кабальных грамот. ${ }^{23}$ Условие о залоге фиксировалось в том же документе, в который заносились условия основного обязательства. Документ, в котором фиксировались условия займа и обеспечивающего его залога, носил название закладной кабалы. Письменная форма займа значительно упрощала судопроизводство в случае принудительного взыскания с должника. Еще в 16 в. англичанин Д. Флетчер (кстати, доктор гражданского права) отмечал, что в отличие от прочих «дела, возникающие на основании записей или письменных обязательств, решаются у них [русских], большей частью, удовлетворительно и скоро». ${ }^{24}$ В 1635 г. «государь царь и великий князь Михайло Федорович всея Руси» указал, чтобы «никакие меж себя ссуды, без кабал и без памятей никто никому не давал и не ссужался», и без кабал и заемных памятей суда не давать. Статья 189 гл. Х Соборного Уложения, принятого в 1649 г., подтвердила это правило: без кабал, заемных памятей против ответчиков суда не давать. Г. котошихин, говоря о сложившейся в Московском государстве практике, писал, что «суд дается по записям»; при отсутствии кабалы суд не дается, «хотя б и двадцать человек свидетелей было, все то ни во что». Статья 254 гл. Х Соборного Уложения устанавливала, что против заемной кабалы допускаются лишь письменные доказательства осуществления платежа по ней.

20 Базанов И.А. Вотчинный режим в России. С. 37.

21 Хрестоматия по истории русского права. Составил Владимирский-Буданов М.Ф. Выпуск третий, издание третье. 1888 г. Прим. 57 М.Ф. Владимирского-Буданова к Указной книге ведомства казначеев.

22 Удинцев В.А. История займа. Киев, 1908. С. 97.

23 Большинство историков права сходятся во мнении, что слово «кабала», арабское по происхождению, вошло в русский язык вместе с монгольским завоеванием: «в татарских официальных документах оно употреблялось в смысле заемной расписки». См.: Зиновьева Е.И. Записные кабальные книги Московского государства XVI-XVII веков: Структура. Лексика. Фразеология. СПб: Изд-во С.-Петерб. ун-та, 2000. С. 44. Флетчер Д. О государстве русском. М.: Захаров, 2002. С. 80. 
Закладные кабалы были обращаемым инструментом. Уже со второй половины XVI в. оборот закладных кабал был явлением распространенным. Передача закладных осуществлялась при помощи так называемой «данной» - передаточной надписи, которая могла совершаться как на самой закладной, так и отдельным документом. Иногда на одной кабале можно видеть ряд передаточных надписей. ${ }^{25}$

Залог, при котором право собственности на предмет залога не переходит к кредитору, может выполнять свою обеспечительную функцию, лишь будучи снабженным свойством следования, т.е. сохраняясь при отчуждении вещи. Свойство следования залога, свидетельствующее об определенном уровне развития залогового права, начинает прослеживаться по некоторым косвенным признакам еще до его первого «официального упоминания» в законодательстве. Впрочем, это не удивительно: тогдашнее законотворчество сводилось к записи уже сложившихся правовых обычаев; случаи иностранных заимствований были редки, а теоретическая юриспруденция тогда в России просто отсутствовала. Появление свойства следования залога можно заметить, читая дошедшие до нас договоры купли-продажи недвижимости и акты, оформлявшие вклады в монастыри. На некотором этапе в них начинает все чаще встречаться оговорка, которую можно выразить следующим образом: «если предмет купли-продажи окажется заложенным по долгам продавца, то последний должен сам уплатить эти долги, не «доводя» их до покупателя». Оборот не воспринимал отчуждение заложенной вещи как основание для прекращения залога: при отчуждении заложенной вещи долг, обеспеченный залогом, ложился на приобретателя вещи. Этому могло способствовать и существовавшее, повидимому, в нашем праве тех лет представление о залоге как о «поручительстве вещи», «обязательстве вещи». ${ }^{26}$ Смысл оговорки заключался в том, что продавец гарантировал отсутствие каких-либо обременений вещи, а в случае обременения вещи залогом обязывался платить лежащий на вещи долг своими деньгами. ${ }^{27}$ Например, в «очищальной записи» 1516 г. продавец обязуется, что в случае обременения проданной им деревни залогом он сам выплатит долг, «не приводя денег» к покупателю. ${ }^{28}$ В купчей 1517 г. продавец пишет: «А если будет то село и деревни по кабалам в деньгах заложено, те деньги по кабалам платить мне». ${ }^{29}$

25 Подробнее см.: Рыбалов А.О. Оборот закладных кабал в русском праве XVI в. // Вестник гражданского права. 2008. № 3.

26 Звоницкий А.С. О залоге по русскому праву. Издание книжного магазина Н.Я. Оглобина. киев, 1912. С. 37 и след.

27 См., например: очищальная запись 1527-1529 гг. (Акты феедального землевладения и хозяйства. Ч. 2. М.: Издательство Академии наук СССР, 1956. С. 103); очищальная запись от 28.05.1554 (Акты служилых землевладельцев XV-начала XVII в. Т. 3. М.: Древлехранилище, 2002. С. 410). 
Подобные оговорки встречаются в русском праве начиная с середины 15 в. ${ }^{30} \mathrm{~B}$ последующем оговорка об «очистке» оформляется в устойчивую формулу, встречающуюся все чаще. Положения об ответственности приобретателя недвижимости по долгам, которые лежат на ней, встречаются и в Литовском статуте 1529 г. (ст. 1 раздела 10). Сейчас трудно сказать: то ли литовское право оказало влияние на отечественное залоговое право, то ли правовые системы развивались параллельно, взаимно дополняя друг друга (во многом благодаря почти непрекращавшимся войнам между Московским государством и Великим княжеством Литовским). как бы то ни было, как видим, в нашем праве свойство следования залога появилось до 1529 г.

В позитивном праве свойство следования залога появляется в Указе Ивана IV от 1558 г. Иван IV установил для «служилых людей» льготный пятилетний срок для выплаты всех существующих долгов, в течение которого долги эти могли быть выплачены без процентов. ${ }^{31}$ При этом царь указал, что если должники заложили свои вотчины с передачей их в пользование кредиторов, вотчины подлежат возврату во владение собственникам-залогодателям, при этом последние не имели права их отчуждать вплоть до полного возврата долга. При этом Указ устанавливал последствия продажи заложенной вещи, переданной во владение залогодателя: если последний, не выплатив долг, продаст, вопреки запрету, заложенную вотчину кому-либо кроме кредитора, долг мог быть взыскан с покупателя заложенной вещи. Если же долг на покупателе «выправить» было нельзя, купленная вотчина подлежала передаче залогодержателю. Покупатель же получал сомнительное утешение в виде возможности взыскивать убытки с продавца заложенной вещи. Можно предположить, что Указ не только официально признал свойство следования залога, но еще и «вбросил» в оборот множество заложенных вотчин, находящихся во владении залогодателей. Это, безусловно, содействовало распространению института: после Указа оговорка «а к (покупателю) тот долг не привести» встречается уже постоянно.

Спорным в истории русского залога можно считать вопрос о том, уничтожало ли установление залога личное требование кредитора о возврате долга. По мнению Л.А. Кассо, по старому русскому праву при установлении залога кредитор не имел права требовать от должника исполнения его обязательства, не мог воздействовать на личность должника: «В наших заемных кабалах залогодатель является обязанным субъектом, но его долг носит тот особенный характер, что эквивалент занятой суммы уже предоставлен кредитору в виде

30 См., например, купчую новгородского Спасского ковалева монастыря: Акты социально-экономической истории Северо-Восточной Руси конца XIV - начала XVI в. Т. 3. М.: Наука, 1964. С. 178.

31 А.А. Зимин полагает, что «эта льгота объяснялась подготовкой к Ливонской войне», начавшейся как раз в январе 1558 г. Зимин А.А. Реформы Ивана Грозного. М.: Издательство социально-экономической литературы, 1960. С. 462. 
залога». ${ }^{32}$ Полагая, что отличительной чертой всех дошедших до нас русских закладных является то, что последствием просрочки залога является приобретение залогодержателем права собственности на заложенную вещь, Л.А. Кассо утверждал, что такое приобретение полностью исчерпывает удовлетворение кредитора, который не может претендовать на что-то еще. ${ }^{33}$

В том же ключе высказывался и Л.В. Гантовер, полагавший, что должник, возвращая обеспеченный залогом долг кредитору, тем самым не исполнял лежащую на нем обязанность, а реализовывал свое право на выкуп вещи; ${ }^{34}$ тем самым ответственность залогодателя распространяется лишь на заложенное имущество. ${ }^{35}$ Эту мысль подхватили и разработчики Проекта ГУ Российской империи: «как и в древнегерманском праве, должник, удовлетворяя верителя, не исполнял тем самым обязанности, лежавшей на нем в силу принадлежавшего верителю права требования, но лишь осуществлял свое право выкупа». ${ }^{36}$

Такой подход решительно отвергался В.А. Удинцевым в работе «Подписка в вере (к учению о древнерусском залоге)»: «ни личного требования, ни иска древнерусский залог не исключает. как должник осознавал и признавал наличность обязанности исполнения главного обязательства, так, с другой стороны, кредитор, несмотря на существование залога, прежде всего имел в виду получение данных взаймы денег». ${ }^{37}$

На основании дошедших до нас закладных можно сделать вывод, что старое русское право залога как минимум не отвергало возможности личного требования к должнику при обеспечении его долга залогом. Например, в закладной (кстати, с двумя совершенными индоссаментами) 1663 г. указывается, что в том случае, если залогодержатель не захочет присваивать заложенное имущество, должник обязан выплатить долг серебром, не ссылаясь на наличие залога. При этом речь идет о возможности судебного взыскания серебра: «где сия кабала меня застанет, под которым судом ни будь, тут по ней суд и правеж и убытки с волокитою на мне, заимщике, а кто с сею кабалою станет, тот по ней истец». как видим, здесь кредитор имеет возможность выбирать между залогом и личным иском даже без попытки предварительного удовлетворения за счет залога. ${ }^{38}$

Кассо Л.А. Указ. соч. С. 211.

Там же.

Гантовер Л.В. Залоговое право. Объяснения к положениям Главы IV Раздела I проекта Вотчинного устава. СПб, 1890. С. 29.

35 Также см.: Товстолес Н.Н. Сущность залога в историческом развитии по русскому гражданскому праву // Журнал министерства юстиции. 1898. № 8. С. 151.

36 Гражданское уложение. Кн. 3. Вотчинное право: проект Высочайше учрежденной Редакционной комиссии по составлению Гражданского уложения. М.: Волтерс Клувер, 2008. С. 501.

37 Гражданское уложение. Кн. 3. Вотчинное право: проект Высочайше учрежденной Редакционной комиссии по составлению Гражданского уложения. М.: Волтерс Клувер, 2008. С. 501.

38 Архив гостей Панкратьевых. XVII - начала XVIII в. Т.2. М., СПб: Альянс-Архео, 2007. С. 87. 
Можно привести достаточно много примеров закладных, оговаривающих последствия недостаточности заложенного имущества для покрытия долга. В таком случае кредитор имел возможность «доправить» недостающее на должнике. Например, в закладной 1648 г. должник закладывает свою пожню и оговаривает, что в том случае, если залог долг «не исцелит», кредитор остальные деньги может получить с заемщика. ${ }^{39}$ В закладной 1548 г. говорится: если заложенная недвижимость «тех денег не стоит, и нам (кредитору) деньги платить». ${ }^{40}$

В других случаях стоимость заложенного имущества превышала стоимость долга. Тогда залогодатель получал возможность получить с кредитора разницу стоимости заложенной вещи и размера своего долга. Например, по закладной... залогодатель занял сорок рублей под залог своей вотчины, и в случае невозврата долга обязался произвести независимую оценку заложенной недвижимости и по результатам оценки получить с залогодержателя превышение стоимости залога над долгом. ${ }^{41}$

Как уже отмечалось, следствием просрочки возврата долга, обеспеченного залогом, чаще всего выступало поступление заложенного имущества в собственность кредитора. Поступление вещи в собственность кредитора вовсе не было «автоматическим». Такой переход совершался записью в книгах Поместного приказа просроченного имения за залогодержателем по ходатайству о том залогодержателя (часто - и залогодателя) или по судебному решению. ${ }^{42}$ Проверка документов в Поместном приказе в некоторых случаях могла занять не один год. ${ }^{43}$

Менее распространенным было удержание вещи кредитором с возможностью пользования ею. Неразрешенным остается вопрос о существовании в русском праве рассматриваемого периода distractio pignoris. Здесь мы сталкиваемся с одним из самых темных мест в истории русского залога. Речь идет о широко известном Указе Ивана Грозного от 1557 г., в котором, в частности, говорится примерно следующее: «Если кто-либо займет деньги на срок под проценты и заложит движимое имущество, но долг вовремя не вернет, залогодержатель должен уведомить должника о том, что если он не вернет долг и проценты, заклад подлежит продаже. Если должник все равно не вернет долг и проценты, заклад подлежит оценке и продаже. С вырученной суммы кредитор получает сумму долга и процентов; излишек возвращается собственнику

\footnotetext{
39 Заемная закладная кабала Павла Севастьянова сына Опарина // Архив гостей Панкратьевых. Т. 2. С. 64. Аналогичные закладные см. там же: с. 73, с. 77, с. 88.

40 Акты Суздальского Спасо-Евфимьева монастыря 1506-1608 гг. М.: Памятники исторической мысли, 1998. C. 142.

41 Акты, относящиеся до юридического быта древней России. Т. 1. СПб, 1857. С. 182

42 Шумаков С. Обзор «Грамот коллегии экономии». Вып. 4. М., 1917. С. 24.

43 Записные вотчинные книги Поместного приказа 1626-1657 гг. М.: Древлехранилище, 2010. С. 1306.
} 
вещи, если же вырученной суммы недостаточно, долг остается на залогодателе».

Д.И. Мейер в своей работе по истории русского права залога утверждал, что эта схема слишком сложна для отечественного юридического быта тех времен. По его словам, «мы не находим никаких указаний в источниках на продажу залога, так что предписание ее представляется неслыханным дотоле нововведением. ... Должно думать, что закон Иоаннов встретил сильный отпор в общепринятом воззрении на право залога и остался без действия: по крайней мере, нет нигде следов его применения к жизни». ${ }^{44}$ Ему вторит Л.А. Кассо: «Это место в названном указе вводит до такой степени крупное нововведение, что нужно или считать его загадочным, или признать за ним значение резкого перехода к новому виду залогового удовлетворения по крайней мере в учении о закладе движимости». ${ }^{45}$ Л.А. Кассо при этом отмечает, что поскольку это место встречается в указе 1557 г., a distractio pignoris в Литовском Статуте появляется впервые в 1566 г., «вряд ли придется искать объяснение первому появлению у нас залоговой продажи в тех романистических веяниях, которые могли проникнуть в Московское Государство через Литву».

Между тем в Указе 1557 г. нет ничего не только неслыханного, но и нового. Л.А. Кассо сам указывает источник заимствования: это Эклога Льва и константина (глава 2 тит. Х). Известно, что не позднее 1262 г. на Руси появились полные переводы таких памятников византийского законодательства, как Эклога, под названием «Главизн премудрых и верных царей Леона и константина», и Прохирон, под именем «Градского закона», которые входили в состав древних сборников, известных под названием кормчих книг. кормчие - своего рода кодексы, включавшие в себя основные памятники церковного и светского права, прежде всего византийские. кормчие были необходимы прежде всего церковным феодалам для церковного управления и суда. При этом, как отмечал Н.М. Карамзин, это собрание законов и правил служило на Руси не только церковным, но и гражданским уложением в случаях, не определенных нашими законами, и дополняло их. Около XIV в. у нас появились, помимо кормчих, особые юридические сборники - «Мерила праведные». Мерило Праведное представляет собой «светский» сборник для княжеского суда, содержащий церковные и светские законы Византии, заимствованные из кормчей, а также древнейшие памятники русского права.

Русское право знает примеры прямого заимствования норм византийского права. Например, в Соборное Уложение из Прохирона были перенесены нормы соседского права: tit. 38 сар. 4, tit. 38 cap. 17, tit. 38 сар. 18 (ст. 277, ст. 
278 , ст. 279 гл. Х соответственно). Таким образом, в обращении к Эклоге по вопросу о порядке обращения взыскания на заложенное имущество нет ничего необычного. Другое дело, что отыскать примеры применения этих положений на практике действительно нелегко. Это может объясняться, в частности, тем, что Указ говорил о залоге движимых вещей, права на которые не подлежали регистрации, и потому соответствующие закладные просто не хранились в частных и государственных архивах.

Впрочем, некоторые документы прямо или косвенно свидетельствуют о возможности продажи залога кредитором. Например, в 1691 г. рассматривалось дело по иску голландца Ивана Фрея о взыскании ста рублей. В деле приводится закладная, согласно которой в случае неуплаты долга кредитор получает право продать заложенное имущество. ${ }^{46} \mathrm{~B}$ другой, более ранней, закладной (1571 г.) идет речь о возможности залогодержателя продать предмет залога, выдав залогодателю hyperocha. ${ }^{47} \mathrm{~B}$ закладной, упоминаемой в завещании 1612 г., говорится о том, что если залогодержатель не захочет оставить заклад за собой, заклад подлежит продаже; деньги от продажи покрывают долг, а излишек возвращается жене залогодателя. ${ }^{48}$ На наш взгляд, вопрос о действии в русском праве distractio pignoris еще ждет своего исследователя.

Таково в самых общих чертах положение дел в сфере изучения залога в русском праве XV-XVII в. На наш взгляд, эта тема еще может послужить почвой для плодотворных исследований и неожиданных открытий.

\footnotetext{
46 Историко-юридические акты 16 и 17 вв. Собрал, описал и принес в дар Археографической комиссии член комиссии М.И. Семевский. СПб, 1892. С. 39.

47 Акты Соловецкого монастыря 1479-1571 гг. Л-д. Наука, 1988. С. 243.

48 Акты феодального землевладения и хозяйства. Ч. 2. Изд-во Академии наук СССР.М., 1956. С. 485.
} 
ESSAY ON MORTGAGE IN RUSSIAN LAW IN THE $15^{\text {TH }}-16^{\text {TH }}$ CENTURIES

This article gives a general overview of mortgage in Russian law in the 15th16th centuries. Antichresis was the most popular form of mortgage at the time. If the debtor failed to satisfy the debt, title to the property vested with the creditor. Such combination of antichresis and lex commissoria gave advantage to the creditor. Nevertheless other types of mortgage were also practiced.

Key words:

Antichresis, lex commissoria, mortgage, history of Russian law. 